\title{
Investigation into Psychological and Social Characteristics of Readiness of Hyperactive Children for Schooling
}

\author{
Nina Mikhailovna Stukalenko \\ Saule Ashotovna Murzina \\ Gulsara Galimbekovna Zhusupbekova
}

Sh. Ualikhanov Kokshetau State University, Kazakhstan, 020000, Kokshetau, Abaya Street, 76

Doi:10.5901/mjss.2015.v6n5s1p349

\begin{abstract}
Children hyperactivity now is a widespread syndrome, which is caused by a child's nervous system disorder due to adverse factors. Readiness of hyperactive children for schooling composes a particular problem. The main problem of hyperactive children at school is inaptitude of their intellectual development to the academic level. The given article is dedicated to the investigation of this phenomenon. The article presents the summarized results of the research conducted on characteristics of readiness of hyperactive children for schooling, which present theoretical and practical value for teachers and psychologists working in preschool institutions.
\end{abstract}

Keywords: children hyperactivity, psychognosis of hyperactivity, readiness for schooling.

\section{Introduction}

\subsection{Relevance of the research problem}

The beginning of school education is a regular stage at a child's life path: each preschool child at a certain age goes to school. For many years the following questions have remained dubious: "At which age is it better to begin schooling: at 6 or at 7 years old?" "Will child cope with the study load?", "How to prepare him/her for school?", "How to help a little pupil when helshe faces first school obstacles?". All these questions worry parents and tutors of the future first graders and they address with them to applied psychologists who work at schools and kindergartens. As the way of each child's development is very individual, they come to school age with different experience - knowledge, skills, and habits. Moreover, it is possible to understand the anxiety of parents and teachers, because future academic progress of a pupil, his/her attitude to study, school and well-being depends on the beginning of the process of schooling

\subsection{Aim and goals of the research}

Aim of the research is to investigate psychological and social characteristics of readiness of hyperactive children for schooling

The following tasks were solved during the process of investigation: analysis of hyperactivity problems in the modern psychology, finding out characteristics of hyperactive children's readiness for school, choice of methods for investigating levels of readiness of preschool children, conducting empirical investigation, processing and summarizing the results of research, drawing conclusions and giving recommendations on the work with hyperactive children.

\section{Methods of the Research}

The following methods were used when conducting the research: theoretical (method of scientific literature analysis, method of comparative analysis), empirical (observation, conversation, survey, psychognostic methods), statistical (qualitative and quantitative research of experimental data). 


\subsection{Theoretical aspects of the research}

Theoretical relevance of the research

Theoretical relevance of the research includes summary and systematization of the theoretic material on the problem of hyperactivity and causes and peculiarities of the phenomenon in preschool children. During the research the syndrome of hyperactivity in preschool children and peculiarities of their preparation for schooling were thoroughly investigated. The analysis of the problem showed that the level of readiness of hyperactive children for school has some peculiarities which are to be taken into consideration when preparing them for school. The notion of readiness for school includes physiological, psychological and social (personal) aspects. These three aspects are closely related with each other. The development of the main systems of a child's organism and his/her state of health compose the basis for school preparation. When it is talked about the readiness for school, the level of physiological, psychological and social development which is necessary for successful digestion of school curricular is implied. (Alferov, 2000)

Types of readiness for school

Physiological readiness of children for studying at school

Physiological development of a child directly influences on educational achievements and is a basis for formation of psychological and social readiness for school. Physiological readiness for school is defined by the level of the development of the main functional systems of a child's organism and the state of his/her health. The evaluation of physiological readiness for systematic school education is given by medical staff according to the certain criteria. It is necessary to take into consideration the level of physiological development and health state of child as they constitute the basis of school activity. Physically weak and frequently ill children even upon the presence of a high level of intelligence, as a rule, undergo difficulties in education (Vinogradova \& Zhurova, 1992). Health record of future first graders should contain detailed information on a child's somatic growth (height, weight, body proportions etc. in respects of age norms) and on the condition of the nervous system. The main criteria of the physiological readiness of children for schooling are: the level of physical development, the level of biological development and health state (Lyutova \& Monina, 2000).

Social (or personal) readiness for educating children at school

Social or personal readiness for education at school represents a child's readiness for new forms of communication, new attitude to the world and oneself, determined by the school education situation. In order to understand the mechanisms of formation of social readiness for education at school it is necessary to consider elder preschool age in the light of 7 years old crisis (Klyueva, 1997). Crisis psychology implies transition periods from one stage of child development to another. Crises appear at the turn of two ages and represent the completion of one stage and the beginning of the next. Dramatic and steep mental change of a child occurs during the crisis periods, so development during such periods is also characterized as negative and even "destructive". At this stage a child does not acquire but loses a lot of that, what was acquired before: an interest to favorite toys and activities fades, a child denies to comply with the rules and norms which were learnt before etc. Any child becomes difficult during crisis periods. The following symptoms of crisis show it very well: obstinacy, cussedness, self-will etc. one of the most important achievements of elder preschool age is realization of his/her social self, formation of inner social position. It is the period when formation of child's personality begins. (Kolominskiy, 1998)

Psychological readiness of children for studying at school

Psychological readiness of a child for schooling - is the readiness to understand some part of the culture, included into the content of education as a form of educational activity. It represents a complex structural systematic education which comprises all aspects of a child's psyche including personal motivational and volition spheres, elementary systems of general knowledge and notions, some scholastic skills, capacities etc. It is not the sum of psychological qualities and characteristics; it is their integral unity which has a definite structure. Important scholastic qualities which are included in the structure of readiness compose complex relations and influence differently on the rate of success at school. In general, readiness of a child for schooling depends equally on physiological, psychological and social development of a child (Bryazgunov \& Kasatikova, 2001).

\subsection{Empirical aspects of research}

\subsubsection{Reasons for chidren hyperactivity}

The research showed that $2 / 3$ of hyperactive children are children from social risk families: bad economic status (one or both parents are unemployed, unsatisfactory living conditions, and homelessness); adverse demographic situation (incomplete families, families with a lot of children, no parents); families with high level of psychological tense (constant 
conflicts between parents, difficulties in relations between parents and children, cruel treatment with children); families with asocial way of living (parents suffer from alcoholism, drug addiction, psychological diseases, behave amorally, commit legal wrongs). Children are practically not paid attention to in families with high social risk (Nizhegorodtseva \& Shadrikov, 2001). Pedagogical neglects contribute to child's delay in mental development. Discontent with communication with close people and lack of emotional contact in seemingly secured families may also be reasons for a child's hyperactivity.

\subsubsection{General description of hyperactive children}

Hyperactive children are children who cannot sit at one place for a long time, they cannot keep silence, obey the instructions. They create more difficulties to the tutors and teachers because they are very active, quick-tempered and irresponsible. They often drop different objects, push their peers and create conflict situations. They often get offended but very easily forget about their offences (Kravtsova, 1991).

The conducted research showed that hyperactive children find it difficult to sit silently; he/she is restless, too talkative and may irritate others with his/her behavior. Very often they have bad coordination or insufficient muscular control. It is difficult for such children to concentrate on something, he/she may easily get distracted, ask a lot of questions but rarely wait for answers. They are not able to concentrate their attention on one object even for a short period of time. They are constantly got distracted by some irrigators and cannot differentiate between main of them. They stop their attention on side effects and thus cannot react to the main ones. Such children's memory has the following characteristics: disorder of attention, easy fatigability, weak cerebrospinal system and other deviations which influence on recording of events and objects in memory. Movements of a hyperactive child have also some specific characteristics. Such children are usually awkward and clumsy. Fine motor skills (uneven handwriting, overextension of letters) and sense-motor coordination (clumsiness) are frequently deviated.

\subsubsection{Main demonstrations of hyperactivity}

Main demonstrations of hyperactivity may be divided into three parts: deficiency of active attention, motional disinhibition, impulsivity (Semenyuk, 2006). Let us consider the main criteria of hyperactivity for observing a child. Deficiency of active attention: child is unsuccessive, he/she cannot hold attention; does not listen when people address to him/her; has a great enthusiasm when begins doing something, but does not complete the task; often loses things; avoids boring tasks which require mental effort; often very forgetful. Motional disinhibition: fidgets permanently; shows signs of anxiety (thrums with fingers, moves in the armchair, runs, hides somewhere); sleeps less than other children even in infancy; very talkative. Impulsivity: has not listened the question till the end, but begins to answer; cannot wait for his/her turn, often interferes, interrupts; cannot wait until the reward (if there is a pause between actions and reward). If till the age of 7 years old parents or tutors observe at least 6 of the mentioned above signs, it can be supposed that the child is hyperactive (Uruktaeva, 2007).

\subsubsection{Practical value of the research}

Analysis of age dynamics showed that the signs of hyperactivity are very marked at preschool and primary school ages: the biggest percentage of children with hyperactivity syndrome is at 5-10 years old. Thus it is possible to conclude that the peak of the syndrome occurs during the period of preparation for schooling and the beginning of schooling (Stukalenko, 2012). The results of the research and our recommendations may be used by applied psychologists for consultations and also by parents and teachers in nurturing and educating hyperactive children.

\section{Experimental Work}

\subsection{Experimental Base}

The study was conducted on the basis of Kokshetau grammar school "Tandau", Akmola region, Kazakhstan. 


\subsection{Experimental Sample}

The preschool children aged 5.5 to 7 years have been the testees. The experimental group of preschool hyperactive children consisted of 30 testees, including 20 boys and 10 girls. The control group of not hyperactive preschoolers consisted of 30 people as well, including 18 boys and 12 girls. During the course of our study we have used a number of diagnostic techniques aimed at identifying hyperactivity disorder and its impact on readiness for school.

\subsection{Research Methods}

\subsubsection{Method of "Defining emotional and personal problems of children"}

To determine hyperactivity there have been used the method of "Determining of emotional and personal problems of children" including five criteria: infantile aggression, over-activity, sleep disorders, learning difficulties, aggressive behavior (Vasilyeva, 1994). Each criterion contains a certain number of symptoms. We identified hyperactivity of a child if he/she had 5 - 7 symptoms. We used the questionnaire for parents. It included 20 symptoms of impulsivity; we identified impulsivity of a child if he/she had 9 - 11 symptoms.

\subsubsection{Comprehensive Study Program of children's readiness for school}

To study the readiness for school we have used the comprehensive program including four techniques aimed at identifying psychosocial maturity, level of development of analytical thinking and speech, as well as school-required functions in the form of the ability to arbitrary behavior (Varga, 1990). The successful implementation of each of the techniques has been evaluated in points; the overall success rate of the child's work on the program has been estimated with the total score for all techniques.

\subsubsection{Method of "Evaluating of psychosocial maturity on the basis of the test conversation"}

With the help of the given method (Wenger, 2001) we have received information about general perceptions of a child, his/her ability to navigate in simple situations, the situation in the family. The conversation was necessary to establish contact with a child, creating an atmosphere of trust in the survey process. At the end of the conversation, we analyzed all the information obtained from the responses to our questions, special attention was paid to the control questions. The final score was calculated by summing all the points. "School-mature" children were considered to be those ones who had received the total of 24-29 points, the average level of school readiness was determined by 20-23 points, relatively unprepared for school life we considered the children who had received 15-19 points. It should be noted that according to the results of the given technique we were able to make only preliminary findings. Further they were confirmed and checked according to the results of the other three methods of the program.

\subsubsection{Method of "Imitation of the written text"}

Completing the tasks of the given method (Wenger, 1994) required the child to show willpower in the performance of not very interesting work, to perform the task in the form of imitation model. The ability of the child to perform such actions is important to master the learning activities. In the process of carrying out such tasks it is also important to determine the characteristics of the fine motor skills, and motor coordination. This makes possible not only to predict the success of writing skills and drawing mastering, but also to conclude (approximately) the development of a child's ability to selfregulate and control the behavior. It is known that the development of fine motor skills is one of the important indicators of mental development. According to the results of the given method we have made the preliminary conclusions about the readiness for school.

\subsubsection{Method of "Thinking and Speech"}

Completing the tasks of the given method by a child (Gavrina, 1998) allowed us to identify his/her understanding of the multiplicity of subjects, the presence of the concept of "one - a lot, " and the notion of grammatical structures on the example of plural nouns, their proper use in accordance with the situation. The diagnosis was made in individual form. The mistakes were considered to be the wrong words and the wrong accents in a word. 


\subsubsection{Method of "Deduction"}

The method (Bogdanova \& Kornilova, 1994) allowed us to investigate the child's ability to draw conclusions according to the proposed model. The job required the ability to establish logical connections and relationships between concepts. Successful fulfillment of the technique allowed us to draw conclusions about the level of verbal and logical thinking on such parameter as a logical action - "reasoning". The survey was conducted in the individual form, and the time for responses was not limited. In the case of the child having obvious difficulties with it, we did not insist upon an answer, and tactfully moved on to the next task. The print of the text was large. The task was to be performed in several stages.

\subsubsection{Method of "Diagnosing the learning motivation of preschoolers"}

Using the given method (Elfimova, 1991) in order to identify how the child is aware of his/her attitude towards the school, we have conducted the individual conversation on such matters: Do you want to go to school? Why? Where do you want to learn more - at school or at home? Why? If you were told you could stay at home for another year, would you be happy or not? Why?

\subsubsection{Method "What am I like?"}

The method (Rean, 2005) is designed to determine the self-esteem of a child of $5-7$ years old. We asked the child how he/she perceived and evaluated himself/herself according to the ten different positive qualities of the person, and we offered several answers (yes, no, sometimes, I do not know).

\subsubsection{General characteristics of the experimental work}

To obtain high-quality and reliable results all the experimental work on assessing readiness for school was held in the office of a psychologist, in a calm and relaxed atmosphere. All the schoolchildren feel relaxed. All the assignments were treated with great interest and responsibility. The conducted empirical study allowed us to obtain the results of great practical importance for teachers and psychologists.

\subsubsection{Reliability of the results of the experimental work}

Reliability of the results of the study is due to the holistic use of psychological concepts, as well as the use of the whole range of techniques which are adequate to the research problems.

\section{Results}

\subsection{Results of the study of the readiness of children entering school}

Table 1 contains the findings of the study.

Table 1. The results of assessing the psychosocial school readiness

\begin{tabular}{|cl|c|c|}
\hline The rate of children's readiness for school & Group "A" (hyperactive children) & Group "B" (non-hyperactive children) \\
\hline 1. & High Rate & $22(73.3 \%)$ & $18(60 \%)$ \\
\hline 2. & Middle Rate & $8(26.7 \%)$ & $10(33.3 \%)$ \\
\hline 3. & Low Rate (conditionally, not ready for school) & 0 & $2(6.7 \%)$ \\
\hline
\end{tabular}

The results of our study have shown that among hyperactive preschoolers there are more children with a high level of school readiness. Moreover, the given group does not contain children who are conventionally not ready for school.

\subsection{Results of diagnosing the method of "Imitation of the written text"}

The results reflect the characteristics of fine motor and motor coordination of children. The level of development of fine motor skills of the hand, small movements is one of the important indicators of mental development. 
Table 2. Results of diagnosing the method of "Imitation of the written text"

\begin{tabular}{|l|c|c|}
\hline The rate of children's readiness for school & $\begin{array}{c}\text { Group "A" (hyperactive } \\
\text { children) }\end{array}$ & $\begin{array}{c}\text { Group "B" (non-hyperactive } \\
\text { children) }\end{array}$ \\
\hline 1. Ready for school & $26(86.7 \%)$ & $20(66.7 \%)$ \\
\hline 2. Ready for school on condition of having attention and control over them & $4(13.3 \%)$ & $10(33.3 \%)$ \\
\hline 3. Not ready for school & 0 & 0 \\
\hline
\end{tabular}

The results have shown that in both groups of children there is predominance of preschool children with high and medium levels of readiness for school. However, the group A has more ready-to-school preschool children.

\subsection{The study results of the method of "Thinking and Speech"}

Table 3 contains the findings of the study.

Table 3. Results of diagnosing the peculiarities of children's thinking

\begin{tabular}{|l|c|c|}
\hline Levels of readiness & Group "A" (hyperactive children) & Group "B" (non-hyperactive children) \\
\hline 1. There are no more than two mistakes (high level) & $20(66.7 \%)$ & $10(33.3 \%)$ \\
\hline 2. There are 3 - 6 mistakes (middle level) & $10(33.3 \%)$ & $20(66.7 \%)$ \\
\hline 3. There are more than 7 mistakes (low level) & 0 & 0 \\
\hline
\end{tabular}

According to the obtained results, hyperactive children possess more developed logical thinking and speech.

\subsection{The study results of the method of "Thinking and Speech"}

While the diagnosing of the intellectual readiness for school, we have studied the children's ability of reasoning according to the model. Table 4 contains the findings of the study.

Table 4. Results of diagnosing the ability of reasoning

\begin{tabular}{|l|c|c|}
\hline Levels of abilities of reasoning & Group "A" (hyperactive children) & Group "B" (non-hyperactive children) \\
\hline 1. High level & $22(73.3 \%)$ & $14(46.7 \%)$ \\
\hline 2. Middle level & $8(26.7 \%)$ & $12(40 \%)$ \\
\hline 3. Low level & 0 & $4(13.3 \%)$ \\
\hline
\end{tabular}

According to the obtained data it is clear that hyperactive children have a higher level of the ability to establish logical connections and relationships between concepts. Considering all the indicators we can state that hyperactive preschoolers have the highest level of readiness for school. Moreover, hyperactive children have better results in reasoning, developed thinking and speech than non-hyperactive children. Analysis of the data showed that hyperactive children had demonstrated a high level of school readiness. So we can conclude that the hyperactivity disorder does not affect the formation of intellectual and psychosocial readiness of preschool children for school. However, teachers and psychologists are to work with these children very carefully because their interest in schooling can quickly go out due to various negative factors.

\subsection{Results of diagnosing the inner position of a preschool child}

To study the internal position of a preschooler, we used the technique of interviews by Nezhnova. We have evaluated the focus on the content of learning activities, the focus on the exteriors of learning activities and school life, the focus on extracurricular activities and conditions. Table 5 contains the findings of the study. 
Table 5. Results of diagnosing the inner position of a preschool child

\begin{tabular}{|l|c|c|}
\hline Main components of the inner position of a preschool child & Group "A" (hyperactive children) & Group "B" (non-hyperactive children) \\
\hline 1. Focus on the content of learning activities & $14(46.7 \%)$ & $14(46.7 \%)$ \\
\hline 2. Focus on the exteriors of learning activities and school life & $10(33.3 \%)$ & $12(40 \%)$ \\
\hline 3. Focus on extracurricular activities and conditions & $6(20 \%)$ & $4(13.3 \%)$ \\
\hline
\end{tabular}

According to the results of the study of the inner position of a preschool child, we can state that a greater number of children in both groups are guided by the content of the learning activities. It should be also noted that the group A (hyperactive children) has more children focused on extracurricular activities and conditions, while the group B has more children focused on the exteriors of learning activities and school life. However, in general, there are no large differences for this indicator.

\subsection{Results of diagnosing the learning motivation of preschool children}

Table 6 contains the findings of the study.

Table 6. Results of diagnosing the learning motivation of preschool children

\begin{tabular}{|l|c|c|}
\hline Rates of learning motivation & Group "A" (hyperactive children) & Group "B" (non-hyperactive children) \\
\hline 1. Educational motive & $4(13.3 \%)$ & $16(53.3 \%)$ \\
\hline 2. External motive & $10(33.3 \%)$ & $10(33.3 \%)$ \\
\hline 3. Gaming motive & $16(53.3 \%)$ & $4(13.3 \%)$ \\
\hline 4. Positional motive & 0 & 0 \\
\hline 5. Social motive & 0 & 0 \\
\hline
\end{tabular}

In the process of diagnosing the learning motivation of preschool children, we have found significant differences between the groups. The gaming motive is predominant among hyperactive children, and the educational motive - among nonhyperactive. The given fact largely explains the difficulties of hyperactive children in adapting to school, as well as their level of discrepancy between the intellectual development and academic achievement.

\subsection{Results of diagnosing the self-assessment of preschool children}

Table 7 contains the findings of the study.

Table 7. Results of diagnosing the self-assessment of preschool children

\begin{tabular}{|l|c|c|}
\hline Variations of self-assessment & Group "A" (hyperactive children) & Group "B" (non-hyperactive children) \\
\hline 1. Very high self-assessment & $4(13.3 \%)$ & 0 \\
\hline 2. High self-assessment & $18(60 \%)$ & $10(33.3 \%)$ \\
\hline 3. Middle self-assessment & $8(26.7 \%)$ & $18(60 \%)$ \\
\hline 4. Low self-assessment & 0 & $2(6.7 \%)$ \\
\hline 5. Very low self-assessment & 0 & 0 \\
\hline
\end{tabular}

The results of diagnosing the self-assessment of preschoolers have shown that hyperactive children possess very high and high self-assessment. Non-hyperactive children mainly have the middle self-assessment - they more adequately assess their strengths and abilities. Therefore, in the process of schooling hyperactive children are often more disappointed with the results of teachings. They expect high marks, incredibly believe in themselves, but the lack of learning motivation and attention deficit prevent them demonstrating high academic achievement. Therefore, hyperactive children are at risk in terms of school exclusion, despite their high potential. The significance of the obtained findings was confirmed with the comprehensive set of methods.

\section{Discussion}

The results of the study were discussed at the scientific seminars of "Actual problems of psycho-pedagogical science and 
modern education" of the Department of Pedagogy and Psychology of Sh. Ualikhanov Kokshetau State University. We believe that it is possible to further the study of psychological and personal characteristics of hyperactive children's readiness for school and to develop guidelines for their teaching and training. The results of this study can be used by psychologists, primary school teachers and preschool teachers to understand, predict the behavior of children and, if necessary, to provide assistance.

\section{Conclusion}

The following conclusions have been made due to the conducted research on the readiness of hyperactive children for school.

1. Hyperactive children have shown a higher level of school readiness, so we can conclude that the hyperactivity disorder does not affect the formation of intellectual and psychosocial readiness of preschool children for school.

2. Hyperactive children have better ability of reasoning than non-hyperactive children, and also have more advanced thinking and speech.

3. In the course of studies of the inner position of a schoolchild it has been revealed that the same number of children in both groups is guided by the content of the learning activities; non-hyperactive preschoolers are more focused on the externals of learning activities and school life, but hyperactive - on extracurricular activities and conditions.

4. The gaming motive is predominant among hyperactive preschoolers, educational motive - among nonhyperactive.

5. Hyperactive children mainly possess very high and high self-assessment, while non-hyperactive children have middle level of self-assessment, i.e. they assess their skills and abilities more adequately.

6. By virtue of insufficient formation of educational motive and overstated self-assessment, hyperactive children are at risk in terms of school exclusion, despite their high potential.

The authors of the article thank the psychologist Olga Mikhailovna Poniatowa of Kokshetau grammar school "Tandau" (Akmola region) for her assistance in conducting the research.

\section{References}

Alferov, A. (2000). Developmental Psychology of a student (p. 120). Rostov-on-Don: Phoenix.

Bryazgunov, I., \& Kasatikova, E. (2001). Restless child (p. 182). Moscow: The art of psychotherapy.

Vasilyeva, T. (1994). Tests for children with the recommendations of a psychologist (p. 114). St. Petersburg: Aktsedent.

Varga, A. (1990). Psychological correction of communication disorder of primary school children (pp. 33-37). Moscow: Family in psychological counseling.

Wenger, A. (2001). Psychological counseling and diagnosis (p. 246). Moscow: Genesis.

Wenger, L. (1994). Is your child ready for school? (p. 218). Moscow: Science.

Vinogradova, N. \& Zhurova, L. (1992). Readiness of a child to school. Tips for teachers and psychologists. The book for parents (p. 280). Moscow: Publishing Prospectus.

Gavrina, S. (1998). Word game (p. 112). Yaroslavl: Publishing World.

Bogdanova, T., \& Kornilova, T. (1994). Diagnosis of cognitive sphere of a child (p. 196). Moscow: Science.

Elfimova, N. (1991). Diagnosis and correction of learning motivation of preschool and primary school children (p. 162). Moscow: Science.

Klyueva, N. (1997). Teaching children to communicate (character, sociability.) The popular guide for parents and teachers (p. 165). Yaroslavl: Development Academy.

Kolominskiy, J. (1998). To the teacher of psychology about the six year children (p. 128). Moscow: Science.

Kravtsova, E. (1991). Psychological problems of children's readiness for school (p. 224). Leningrad: Aktsedent.

Lyutova, E., \& Monina, G. (2000). Psycho-correcting work with hyperactive, aggressive and anxious children (p. 206). Moscow: Genesis.

Nizhegorodtseva, N., \& Shadrikov, V. (2001). Psycho-pedagogical readiness of a child to school (p. 268). Moscow: Non-science Publishing Center "Vlados".

Rean, A. (2005). Practical psychology tests or how to learn to understand yourself and others (pp. 24-28). Moscow: Genesis.

Semenyuk, L. (2006). Psychological features of hyperactive behavior of adolescents and the conditions for its correction (p. 160). Textbook. Moscow: Flint.

Stukalenko, N. (2012). Educational Psychology (p. 110). Textbook. Astana: Publisher: Gumilev ENU.

Uruktaeva, G. (2007). Preschool psychology (p. 196). Textbook. Moscow: Academy. 